\title{
Use of Social Networks to Affect the Teaching and Learning Effectiveness of 3D Design
}

\author{
Ting-Sheng Weng \\ Department of Business Administration, National Chiayi University, Chiayi 600, Taiwan, R.O.C.
}

\begin{abstract}
In recent years, with the rapid development of technologies, information technological software and social networks have been widely accepted. Therefore, social networks can be integrated with information technologies for teaching purposes. In addition, the sharing of learning outcomes via social networks can improve students' learning effectiveness. This study used an information technology teaching environment to teach students 3D skills, and used 3D SketchUp to enable students to explore, operate, and complete their personal works by themselves. Moreover, this study used Facebook as the media of a WBI (web-based instruction) community, and used the discussions and sharing between students and students, and students and teachers, to improve learning effectiveness and reduce learning disabilities. The research results showed that, proper use of social networks to provide students with opportunities to discuss and share outcomes can help improve students' learning effectiveness and reduce learning disabilities.
\end{abstract}

Key words: Learning effectiveness of social network, community identity, network information sharing, learning disabilities.

\section{Introduction}

The development of information networks enables course instruction to advance to multimedia instruction through the assistance of network sharing platforms and information software. SketchUp is free software developed for the purpose of creating 3D models [1]. In terms of learning effectiveness, Hsu [2] at the Computer Center, Academia Sinica used Google SketchUp to draw 3D models. Google SketchUp can be used to rapidly and easily construct or modify 3D models, and allows placing the designed 3D models in real world coordinates. In addition, it enables users to share their personal creativity and designed works with everyone in the world through the Google 3D Warehouse. Due to the rapid development of social networks, students can also use social networks to share assignments with classmates or other friends to improve learning effectiveness. Shafer [1] put research focus on basic tools of procedures and how to use the functions to support students to learn prism

Corresponding author: Ting-Sheng Weng, Ph.D., research fields: science technology and management, e-learning, information education, technology education, MIS, and image processing. and pyramid. In addition, he indicated that, SketchUp can support students' learning through inquiry. Moreover, at present, SketchUp is easily available software. The study by Kuo and Chuang [3] demonstrated that the integration of modern technologies provides effective methods to help teachers and students to consider creative design, as well as developed solution packages, including the technologies of Google SketchUp, 3D Warehouse, and Microsoft Virtual Worlds. When students can visualize that, compared with the use of commercial software, they can spend less cost and effort, as well as display the digital games that they designed, the feasibility of a solution package can be proved.

\section{Motivation and Purpose}

With the rapid development and comprehensive application of emerging technologies, computers and the internet have become more common, and their functions have changed with each passing day. Moreover, information technologies have generated wide and deep impacts on modern human life. What concepts, knowledge, and skills of information technologies should students possess? How to help 
students develop the basic ability of computational thinking to enable them to be competitive in a global society of information technology is very important. Therefore, teaching methods should be more diversified, and teaching should not be simply implemented using the traditional blackboard. This study used 3D virtual reality teaching to display what cannot be easily displayed in traditional blackboard teaching, such as dynamic 3D images, to further improve students' concepts and skills of information technologies. However, with the development of social networks, apparently social networks have become the tool through which students transfer and share information. Therefore, students can share everything in life, including assignments and learning outcomes, through social networks. As a result, this study intends to investigate the following issues:

(1) Can 3D virtual reality teaching improve students' learning effectiveness of learning software?

(2) Can the sharing of 3D skills and information on social networks improve students' learning effectiveness of learning software?

(3) To use the information sharing of social networks to reduce learning disabilities and improve learning effectiveness.

(4) To observe the intermediary effect of students' community identity.

\section{Literature Review}

\subsection{Level of Interaction of Virtual Community}

A virtual community is an individual in real life. By using network information technology, an individual can develop interpersonal relationships to accumulate knowledge through exchanges, interactions, and information sharing of an information exchange model in a specific information space within a certain period of time [4]. Tsai and Lai [5] summarized and indicated that, the existing virtual social networks can be classified according to many different factors. However, their purpose of establishment and focus of members' discussions are mainly common interests.
Therefore, among the definitions of virtual communities, common interest shared by community members is the concept that all scholars constantly emphasize, as well as the main reason why the members gather. Lu [6] also indicated that virtual interpersonal relationships enable users to develop intimacy and emotional interactions. A virtual context can be a place where emotions can be exchanged and vented.

Juang [7] mentioned that Games-Based Learning is the field that many learning researchers have been aggressively developing in recent years to enable learners to feel the challenges, control, sense of mystery, and sense of satisfaction of games. In addition, such games can be assisted by social interaction software or websites, such as Facebook, Twitter, MSN, and Plurk. The main objective of game-based learning is to enable users to maintain interactions with friends they know in real life, as well as to expand their social interaction networks through the exploration fun of social interaction games. Therefore, Social Learning Games can improve students' learning motivation, create a positive learning attitude, and increase teacher-student interaction and the level of peer interaction to further improve learning achievements.

\subsection{Community Identity}

Wu, Fang, and Huang [8] mentioned that "community identity" is derived from the social identity theory. According to the definitions, community identity is composed of two common concepts: one is identity itself, namely, the sense of belonging to a community; the other is the part concerning identity and self-concept [9]. The strength of relationship between a member and a community can be assessed based on the concept of community identity. Based on such a concept, one can judge whether he or she can become a member, namely, a member belonging to the community of the virtual brand [10]. In recent years, virtual communities have 
become increasingly popular. Although there is a significant increase in the number of communities, there is a relatively small number of studies investigating information sharing [5], and only very few communities can successfully improve community members' knowledge sharing [11]. Therefore, it is important to enable members engaging in learning in class to discuss with one another on Facebook community to make them understand knowledge sharing behavior of community members. Thus, this study encouraged students to log into the online Facebook community of a software application course, as this study intends to understand the influence of sharing the learning skills and feedback of community members, and observe the influence of the 3D works of other people on students.

\subsection{Learning Difficulties}

Chuang [12] mentioned that e-learning is a future trend. However, the starting point of learning for everyone is different. Learners lacking in background knowledge tend to easily develop learning disabilities. If learners' personal level and objective are understood, and appropriate courses are arranged, integration of network and development of proper modular e-learning can achieve the maximum learning effectiveness. Hung, Wu, and Hsieh [13] used 3D and virtual reality technology to develop a "virtual reality network learning platform", and used them-based design to design 3D e-book materials suitable for students with learning disabilities in elementary school mathematics, in order to improve students' learning effectiveness in contextual learning environments through teaching.

The Internet plays a very important role in the integration of information technology and teaching. Students taking multimedia courses are from different schools, and their background knowledge and skills are different. Therefore, providing teaching materials outside the learning platform, using the virtual platform of the Facebook community to provide students with answers to questions in a timely manner, and providing skills and procedures can enable students encountering problems in class or out of class to immediately obtain problem-solving skills. The integration of information technology with teaching has become an educational trend. If network learning environments can be fully utilized, instructors and learners can engage in individualized interactions of learning needs, reduce learning disabilities, improve teaching quality, and improve teaching and learning effectiveness without being limited by time or space.

\subsection{Learning Effectiveness}

Based on the perspectives of situated learning, problem-based learning, and social constructivism, Chu, Chen, Hung, and Liao [14] focused on cooperative learning to integrate the characteristics of cognitive theory and e-learning, and refer to the knowledge transformation methods of knowledge management to develop the "adaptive cooperative e-learning model”, which aims at improving the professional growth of students with learning difficulties in mathematics for teachers using systematic, structured, adaptive, and tacit knowledge induction in their teaching knowledge and ability. They then designed and constructed the system based on the above, and investigated the effect of this model on improving teachers' knowledge and ability and students' mathematics learning. Chan [15] suggested that the outcome focus is not on students' academic performance, but the ability actually developed by the end of the learning process. In addition, he used students' performance to inspect educational outcomes. Specifically, outcome-oriented education emphasizes the development of a learning blueprint that can predict students' performance outcome, the development of specific outcomes and performance standards, and stage-by-stage assessment on learning outcomes during the learning process to ensure that graduates possess the required abilities. Liao and Huang [16] integrated social network services with 
electronic illustrated stories to provide teaching activities that are combined with natural science courses in elementary schools. In addition, a platform with abundant content for knowledge transfer and cooperative learning triggered students' learning motivation and interest, developed the communicative and interactive relationship between teacher and students, and improved students' learning and learning satisfaction to further improve their learning effectiveness. The currently popular social networks have been widely accepted by users and applied to various fields. Facebook is one of the most popular current social networks. It provides powerful interactive functions and assists learners in developing the relationship of cooperative learning. The study by Liu [17] suggested that, compared with the traditional classroom teaching model, a network learning environment enables learners to have more channels and courage to ask questions when faced with problems, and has a significant benefit on improving students' problem-solving ability. In addition, learners suggested that, the network learning model provides learners with more diversified learning. Moreover, the hyperlink feature of networks enables learners to search course-related resources online in a timely manner during the learning process, and enables them to absorb more extracurricular knowledge and expand the learning vision of courses.

This study used on-site teaching and instant community discussions in classroom teaching, provided individual instruction for students' questions, and uploaded the operating procedures of 3D production to teaching platforms and community discussion websites. This study also recorded the difficulties encountered by students on social networks in order to provide instant solution skills as reference for other students.

Due to the popularity of network platforms, contemporary students are used to using social networks for communication. Some students are not good at engaging in face-to-face verbal communication with people; therefore, this instant social network enabled students who seldom raise questions verbally to use textual conversion for interaction.

\section{Research Method}

This study provided 3D software for students to produce 3D digital products in software courses, and used the social network software of the Facebook club forum to enable students to discuss works and share production skills and procedures with one another. The author acted as course instructor, and used Facebook to interact with students. During the course, the author implemented individual teaching and obtained feedback. Finally, this study performed literature review, analysis, and investigations.

\subsection{Research Design}

In the beginning of learning, this study encouraged students to explore the functions provided by computer software. In addition, at the appropriate time, this study requested students to exchange feedback, and encouraged creators to keep trying trends as the requirement for good creation. This study encouraged students to use Google SketchUp 3D software to produce 3D works, upload their works and design concepts on the Facebook club interface to enable the teacher, or other students participating in the course, to provide feedback, and immediately provide online skill support to one another according to the feedback and 3D works instantly shared online. In this way, students could improve their own works through the assistance of other people (see Figs. 1 and 2).

The reason why this study used Facebook as the social network discussion platform is that the popularity of Facebook in Taiwan is the highest in the world. According to the user data in Taiwan, as announced by a Facebook official in 2013, an average of 14 million people use Facebook every month in Taiwan, approximately 10 million people log into Facebook every day, and 7.1 million people log into 


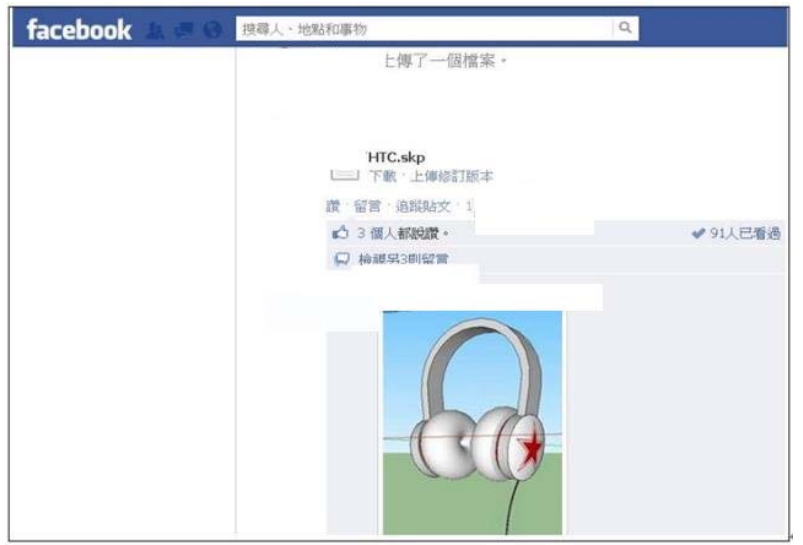

Fig. 1 Students shared their works on social network.

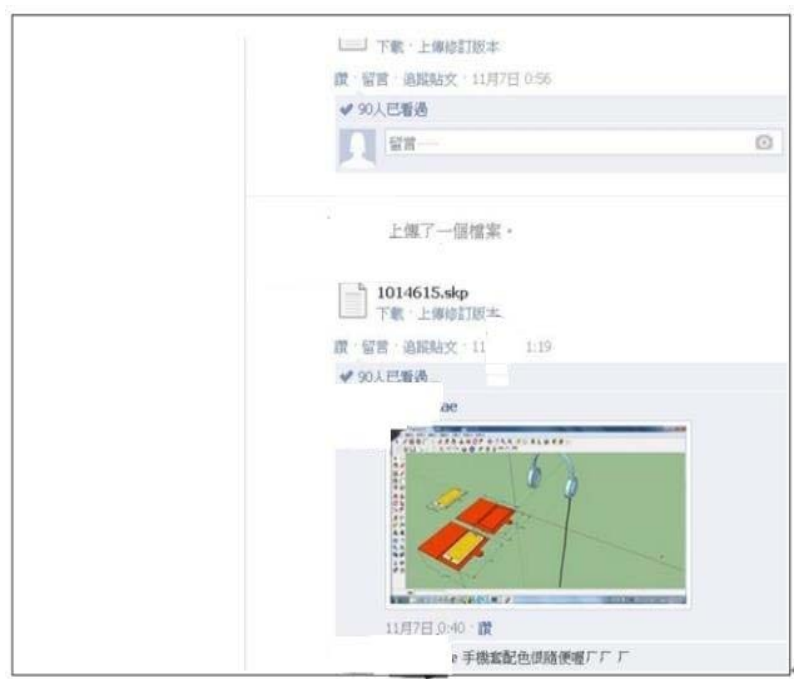

Fig. 2 Students instantly shared their works on social network and obtained instant discussion feedback.

Facebook via smart phone or tablet computer. The proportion of active users who use Facebook at least once daily is $71 \%$, which is higher than the $67 \%$ in Hong Kong and the global 61\% [18].

Students could instantly share their works with other classmates, and could also learn the creativity and design concepts of others from social networks. Moreover, students could interact with one another to enhance their learning atmosphere.

Instant sharing social networks could become an efficient learning model, which would be beneficial to the improvement of technological ability and enable learners to instantly obtain discussion feedback to improve learning effectiveness without being limited by time or place. Learners could immediately learn design concepts that are different from theirs, as well as refer to other people's works to integrate with their original works and become new works. Such instant sharing learning effect could obtain the maximum feedback.

\section{Results}

This study used 3D SketchUp as the teaching material in class, and observed students' learning situations through the community platform. The outcomes of teaching students to use software are, as follows:

In an era of high quality and precision, size precision is an important concept, where only $100 \%$ precision can meet the needs of society. Products in Taiwan are featured by high precision. However, the proverb in Taiwan: "Just the same is acceptable" may sometimes lead to students' misconceptions. The difficulty of designing 3D structures using a planar computer is visual angle. Only when a structure is observed from multiple visual angles can defects or poor design be discovered. Highly precise 3D works cannot be designed unless constantly turned within a space for various visual angles to inspect whether there are errors, and the errors are further corrected.

This study took the erroneous 3D visual design for example to give explanations. As shown in Figs. 3-5, this study gave explanations of front view (Fig. 3), plan view (Fig. 4.), and magnified view (Fig. 5.), respectively. From the front view of Fig. 3, the positions of lines seem to be correct. However, from Fig. 4, the plan view, the design positions of lines are wrong. From Fig. 5, the magnified view, the positions of lines are wrong.

In the book, How Is Society Possible? Simmel [19] mentioned that, the existence of society is established upon the interactive relationships among people. The purification process of interactions and social patterns is called socialization. According to Simmel's assumption, human beings are inclined to socialization. During the socialization process, human beings will 


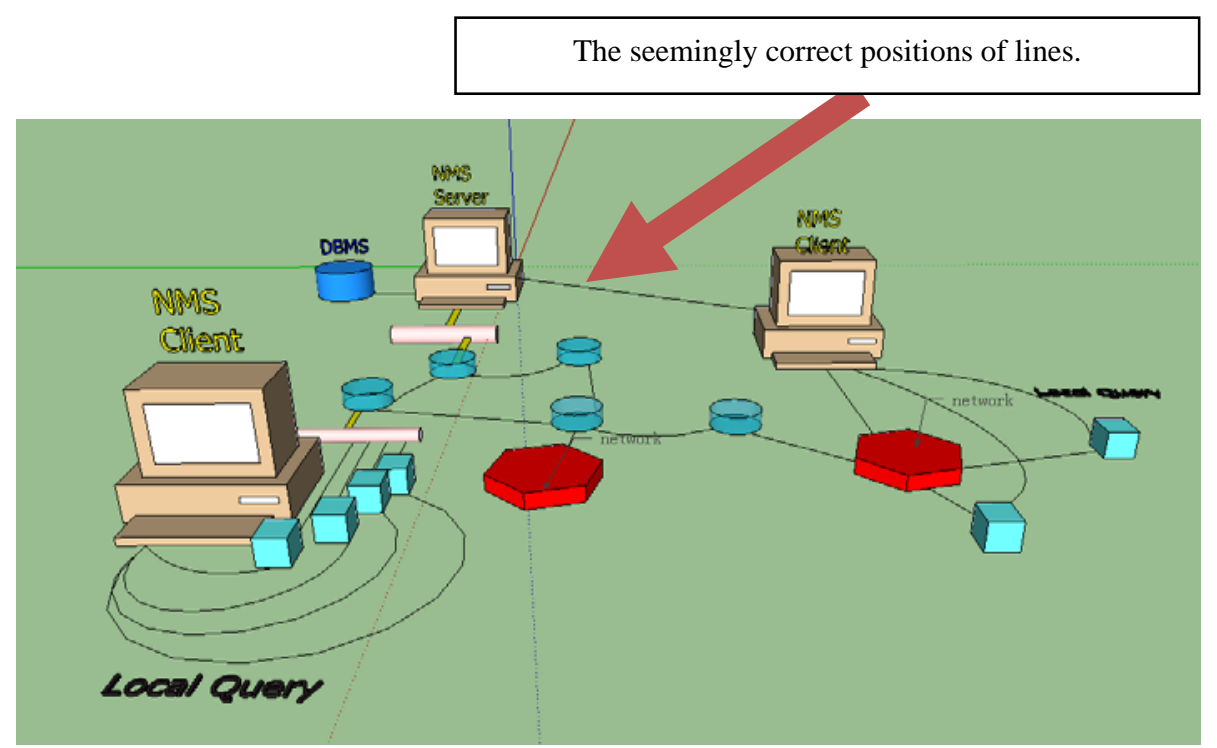

Fig. 3 The front view shows that the positions of lines seem to be correct.

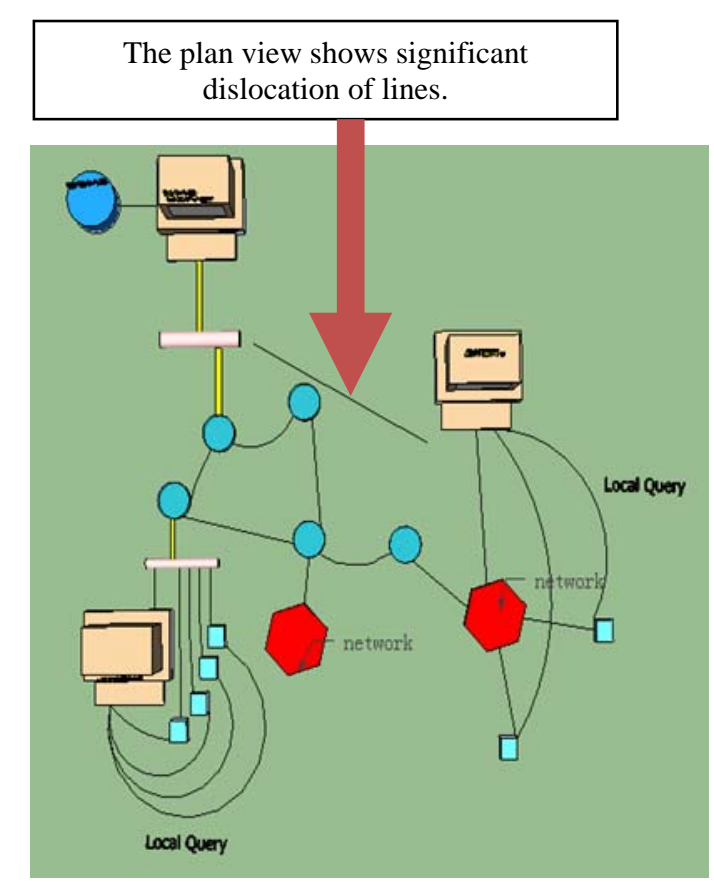

Fig. 4 The 3D plan view shows the dislocation of lines.

experience three stages: stage 1 -confirming that other people are a part of our group; stage 2-group is affected by non-socialization through interactions. During this process, members adjust themselves, and eventually reach autonomous existence; stage 3-the group is aware that the society is composed of unequal structures where inequality and imperfection exist. However, group members still agree that society is the

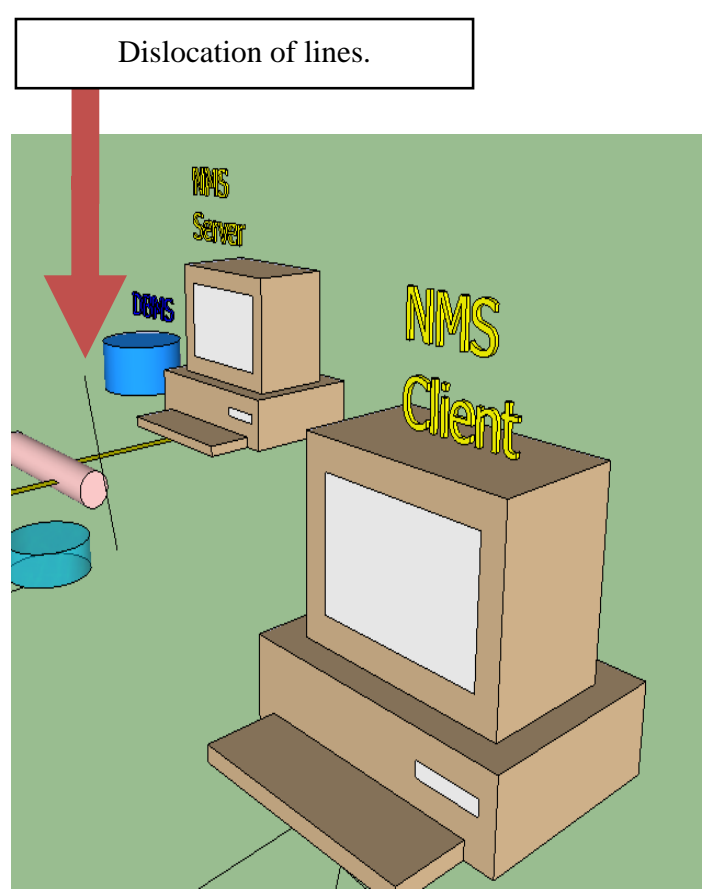

Fig. 5 The magnified view shows the dislocation of lines.

platform of interpersonal interactions. In this way, the process of social practice can be completed [20].

When performance on a platform is similar, students will spontaneously form groups. However, some students are still non-socialized. Overall, during the learning of 3D SketchUp, students would discuss assignments and software skills with one another on the social network. Therefore, peer learning could be 
effectively utilized to help other students, which has significant impact on the development of positive learning power.

\section{$5.13 D$ Virtual Reality Teaching Improved Students' Learning Effectiveness of Learning Software}

In terms of education, 3D virtual reality can develop the 3D space concept of users, reduce the difficulty of converting 2D images to 3D structures, and convert general 2D images to virtual reality actually operated by users, which is the ideal combination of 3D technological software with education. Application of $3 \mathrm{D}$ virtual reality software enables learners to interact with learning materials, provides them with the feeling of personal experience, and offers them opportunities for storage, integrated alignment, value-added application, and easiness of repeated practice. 3D virtual reality software displays 3D virtual environments, and users can interact with virtual environments through the human machine interface to personally experience 3D structures. With students' active participation, 3D simulation can effectively assist students in understanding abstract knowledge, thus, enhancing their learning motivation and improving the learning effectiveness of the application of 3D design.

As human beings live in an environment of information technology, human life is closely related with such information network systems. Therefore, during the design of a 3D information network system, students could also understand the meaning of connection with an information network system. The use of 3D virtual reality teaching enabled students to experience the context. In addition, on-site and web-based instruction provided students with better understanding of learning of software, and enabled them to achieve great learning effectiveness.

\subsection{Information Sharing of 3D Skills on the Social} Network Improved Students' Learning Effectiveness of Learning Software

In an era of rapid development of information technology and social networks, students' sharing is no longer restricted to face-to-face sharing, and they can use social networks to instantly exchange opinions with others or learn from one another. In this way, the conversion of cognitive form can be reduced. The 3D skills information sharing of social networks has significant learning software application effectiveness for the application of situated learning. However, 3D and users can maintain an interactive relationship. With the operational design and color rendering of users, 3D virtual environments can generate different works of diversified designs.

\subsection{Information Sharing of Social Network Reduced Learning Disabilities to Improve Learning Effectiveness}

The learning methods, knowledge, and skills background of everyone are different. If proper courses in combination with e-learning can be arranged, and peers can be utilized to share knowledge and skills on social networks, learning effectiveness can be improved to reduce learning difficulties.

3D interactive functions enabled learners to observe the relative positions of an information network system from various angles in a space, and connect the precise positions of adhesion points, lines, and surfaces of network cables. Moreover, with the interactive information sharing and discussions of social networks, learners' burden of design imagination can be reduced, and they can advance to learning the fundamental principles of an information network system.

\subsection{Observation on the Intermediary Effect of Students' Community Identity}

Community sharing can stimulate learning. The intermediary effect of social networks on students was to use social networks to learn from and share with other classmates, and trigger their learning interest. Interaction, immersion, and imagination possessed by 3D technology offer the potential of development of 
space design and product teaching and design. Therefore, teaching 3D software application will be an indispensable part of future educational research.

\section{Conclusions}

Chen [21] used a web-based instruction platform to introduce multimedia reciprocal representation teaching materials to implement experimental teaching and assess learning effectiveness, in order to investigate the differences in learning motivation and effectiveness, as caused by different teaching strategies and teaching materials. The study found that, the training of mixed e-teaching strategies and multimedia reciprocal representation teaching materials can improve learners' learning motivation and effectiveness, and help increase the understanding and memory of learning content to better preserve learning effect. The study by Lai [22] found that, the introduction of Web 2.0 platform to the design of learning activities has positive influence on the learning effect of self-adjustment. For example, it can improve learners' intention to communicate and share, which is beneficial to learners' reflection. Moreover, it enables learners to internalize knowledge and apply it to learning. In addition to human resources personnel, a network learning platform integrated with Web 2.0 tools enables instructors to better flexibly arrange learning activities and make the learning atmosphere more vivid.

$\mathrm{Yu}, \mathrm{Yu}, \mathrm{Lu}$, and Chiu [23] indicated that, if virtual communities intend to increase the number of members and activate the internal knowledge transfer of communities, they can achieve such objectives by developing social exchange relationships, encouraging altruism, and creating community identity to enable members to share knowledge and provide feedback. Moreover, the higher the level of a social exchange relationship between community members and other members is, the higher the perception of altruism, sense of community belonging, and internal knowledge sharing in communities is. Virtual communities with high knowledge sharing can effectively share and convey knowledge and experiences, which may help communities engage in knowledge management.

Information technology with computer graphic tools enables users to fulfill unlimited creative creation. Computer graphics technology is not merely a tool, but actually a media affecting human beings' thinking, as well as their attitude towards computers. Technology improves the efficiency of teaching and enables students to find more joy in learning.

Computer graphics can combine objects of different lines, colors, and shapes to rapidly fill in the colors of objects or remodify them. Students can rapidly learn to attempt different creations, and are provided with the space of visual imagination and digital creativity. This study enabled students to design a 3D computer network system, and use the concepts of an information environment to design a 3D computer network system model. Therefore, this study could improve the visual value of a space information environment perceived by students. Through 3D surround view, the precision of every surface could be observed from $720^{\circ}$.

Compared with traditional media, computers provide safer environment. Therefore, students were not worried about contamination of digital objects, and could explore and attempt designs without hesitation. During the teaching process in class, the author integrated information technology with interactive teaching, and achieved great learning effectiveness. Therefore, during the teaching process, the author guided students to learn dynamic 3D and trained their production precision. Moreover, students could observe the creative works of one another through social network platforms to avoid interference of close observation from others during the design process. The author found a lot of joy in teaching because the learning effectiveness of students was improved during the teaching process. 


\section{Recommendation}

Future studies are advised to analyze and investigate the moderating (intervening) effects of intermediary variables of the problem-solving ability of the 3D space concept, 3D skill learning, and their mutual influence on learners during peer learning.

\section{References}

[1] Shafer, K. 2010. "Prisms and Pyramids with Google SketchUp: A Classroom Activity.” In Proceedings of Society for Information Technology and Teacher Education International Conference 2010, edited by Gibson, D., and Dodge, B. Chesapeake, VA: Association for the Advancement of Computing in Education (AACE), 3505-7.

[2] Hsu, W. G. 2010. "Application of Landform, Architectural 3D Model-Related Techniques and Virtual and Real Statuses.” Academia Sinica Department of Information Technology Services, Academia Sinica Computing Centre (7).

[3] Kuo, M. S., and Chuang, T. Y. 2012. “A Time and Cost Effective Approach to 3D Scenario Building in a Digital Game Design Class.” Procedia-Social and Behavioral Sciences 64: 209-18.

[4] Sun, Z. C., Gao, H. C., Chang, C. S., and Wang, T. C. 2009. "Information Exchange Behavioral Pattern of Virtual Community Members.” In Proceedings from International Conference on Information Management 2009. Taipei: Shih Hsin University.

[5] Tsai, C. H., and Lai, L. L. 2011. "Information Sharing of the Virtual Community." Journal of Library and Information Studies 9 (1): 161-96.

[6] Lu, R. Y. 2013. "A Study on Community Awareness, Community Dependence, and Community Civil Behavior in Virtual Communities.” In Proceedings from 2013 the 16th Conference on Interdisciplinary and Multifunctional Business Management. Taipei: Soochow University.

[7] Juang, Y. R. 2013. "Research on Design, Application and Evaluation of Mobile Social Learning Game for Highly Interactive Learning.” National Science Council Project, NSC101-2511-S228-001-MY2. Taipei: National Science Council, Executive Yuan.

[8] Wu, S. C., Fang, W. C., and Huang, H. C. 2012. "Identifiable Anonymous and Group Norms in Virtual Communities: The Test of Mediating Effects of Public Self-awareness and Community Identification.” Journal of Information Management 19 (2): 315-47.

[9] Mael, F. A., and Ashforth, B. E. 1992. “Alumni and Their Alma Mater: A Partial Test of Their Formulated Model of
Organizational Identification.” Journal of Organizational Behavior 13 (2): 103-23.

[10] Algesheimer, R., Dholakia, U. M., and Herrmann, A. 2005. "The Social Influence of Brand Community: Evidence from European Car Clubs.” Journal of Marketing 69 (3): 19-34.

[11] Lai, H. M. 2013. "Sharing Information and Rumors in Online Communities-A Comparison of Posters and Lurkers.” National Science Council Project, NSC101-2410-H270-002. Taipei: National Science Council, Executive Yuan.

[12] Chuang, K. C. 2008. “The E-Book Combined Digital Learning Platform.” National Science Council Project, NSC97-2511-S224-001. Taipei: National Science Council, Executive Yuan.

[13] Hung, M. C., Wu, C. L., and Hsieh, T. C. 2013. “The Investigation, Implementation, and Evaluation on the Math E-Book Based on 3D Virtual Reality for the Elementary School Students with Math Learning Disabilities from the Perspective of Situated Cognition.” National Science Council Project, NSC101-2511-S343-001. Taipei: National Science Council, Executive Yuan.

[14] Chu, H. C., Chen, Y. M., Hung, P. S., and Liao, M. R. 2010. “A Study of Adaptive Collaborative E-Learning for Teachers' Professional Development on Knowledge and Competence about Teaching Students with Mathematical Learning Difficulties.” (III) National Science Council Project, NSC99-2511-S024-015. Taipei: National Science Council, Executive Yuan.

[15] Chan, H. H. 2011. "Influence of Assessment Mechanism for Students' Learning Effectiveness on University Education and Reflection.” Taiwan Educational Review Monthly 1 (2): 43-5.

[16] Liao, Y. W., and Huang, Y. M. 2013. “Cooperative Learning Platform for the Recommendation Mechanism Based on the Story Electronic Picture Books to Social Networking Sites.” National Science Council Project, NSC101-2622-S041-001-CC3. Taipei: National Science Council, Executive Yuan.

[17] Liu, D. Y. 2007. "Influence of Interactivity of Network Learning Environment on Learning Effectiveness of University Courses." Chia-Nan Annual Bulletin 33: 429-46.

[18] Lin, D. H., and J\&M Studio Cultural Creativity. 2014. “Facebook’s Must-Try Marketing Strategies: Use of 15 Tricks to Create Your Own Network Marketing Channels.” New Taipei: Lingjixian Publishing.

[19] Simmel, G. 2002. How Is Society Possible? Translated by Lin, R. Y. China: Guangxi University Press. (Original work published in 1908).

[20] Yang, E. F. Y., and Liao, C. C. Y. 2009. "Exploring 
Online Community Formation and Identity Trajectory from MMORPG Players' Motivation.” Journal of Cyber Culture and Information Society 17: 185-204.

[21] Chen, Y. T. 2010. "The Study on the Combination of Teaching Strategy for Examining Learning Performance." Journal of Tainan University of Technology 29: 191-212.

[22] Lai, H. J. 2014. “An Analysis of Using Web 2.0
Platforms in Online Self-regulated Learning.” Training \& Development Fashion 182: 1-17.

[23] Yu, C., Yu, C. C., Lu, S. C., and Chiu, Y. P. 2013. “A Studying of Using Social Exchange, Altruism, and Community Identification to Investigate the People's Behavior in Virtual Community of Knowledge Feedback-Knowledge Sharing as the Mediator Variable.” Training \& Development Fashion 178: 1-45. 